\title{
Residência pedagógica: processos didáticos e formação docente em uma escola municipal de ensino fundamental
}

Pedagogical residency: didactic processes and teacher training in a municipal elementary school

\author{
Brunela Santana \\ Mayra Gomes Pacheco \\ Laís Reges Martins \\ Christiane Vieira de Andrade \\ Gustavo Machado Prado
}

Resumo: A licenciatura é uma das principais etapas do processo de formação docente. No decorrer desse período, espera-se que o futuro educador adquira conhecimentos para atuar no processo ensino-aprendizagem de forma clara, objetiva e motivadora. Visando subsidiar os cursos de licenciatura nesse processo, a CAPES criou o Programa Residência Pedagógica, com os objetivos de ampliar o tempo de permanência e prática dos graduandos na escola e fortalecer a relação entre instituições de ensino superior e escolas da educação básica. O presente artigo traz o relato de intervenções didáticas realizadas por três residentes do curso de Ciências Biológicas da Universidade Federal do Espírito Santo em uma escola de ensino fundamental do município de São Mateus, ES. A escola foi selecionada pela Secretaria Municipal de Educação para ser uma das participantes do programa devido aos seus baixos indicadores educacionais. As residentes trabalharam junto à preceptora por 18 meses e elaboraram e desenvolveram práticas escolares e atividades educativas como forma de auxiliar o aluno no entendimento do conteúdo abordado. As atividades realizadas resultaram em uma participação mais ativa e interessada por parte dos alunos da escola, possibilitando uma aprendizagem significativa dos conteúdos de ciências. Além disso, as residentes puderam aprofundar suas experiências formativas e a professora preceptora pôde conhecer novos procedimentos didáticos, aprimorando sua prática profissional.

Palavras-chave: Atividades Educativas, Ciências, Formação Docente, Realidade Escolar.

Abstract: The degree is one of the main stages of the teacher training process. During this period, it is expected that the future educator will acquire knowledge to act in the teaching-learning process in a clear, objective and motivating way. Aiming to subsidize undergraduate courses in this process, CAPES created the Pedagogical Residency Program, with the objectives of extending the time spent by students at school and strengthening the relationship between universities and primary schools. This article presents the report of didactic interventions carried out by three residents of the Biological Sciences course at the Federal University of Espírito Santo at a primary school in the city of São Mateus, ES. The school was selected by the Municipal Secretary of Education to be one of the program's participants due to its low educational indicators. The residents worked with the tutor for 18 months and developed and developed school practices and educational activities as a way to assist the student in understanding the covered content. The activities carried out resulted in a more active and interested participation of the school's students, enabling a meaningful learning of science content. In addition, the resident graduates were able to deepen their training experiences and the tutor teacher was able to learn about new 
didactic procedures and incorporate them into her professional practice. In addition, the resident students were able to deepen their training experiences and the tutor teacher was able to learn about new didactic procedures, improving her professional practice.

Keywords: Educational Activities, Sciences, Teacher Training, School Reality.

\section{Introdução}

A profissão de professor, historicamente, se constituiu devido a intervenção do Estado, que substituiu a igreja no papel de organizadora do ensino. Com as condições para essa atividade estabelecidas, os professores então se tornaram a voz da escolarização. Para tanto, mais do que a formação em áreas específicas da ciência, é necessária uma formação de professores para que assumam papel eficaz na área docente, unindo a lógica da atividade educativa com as dinâmicas da formação (NÓVOA, 1991).

O processo de formação não é baseado em cursos ou técnicas somente, abrangendo também a reflexão crítica acerca das práticas e da identidade pessoal e profissional. Está interligado aos percursos e modelos educativos, com a pedagogia do que é educar e, assim, é um processo que está em constante mudança com o passar do tempo (DOMINICÉ, 1986). Para Pimenta (1997) a formação de professores objetiva conceder habilitação à ação profissional docente de forma que desenvolvam conhecimentos, habilidades, ações e valores unidos ao exercício de ser professor.

Em 2018, a Coordenação de Aperfeiçoamento de Pessoal de Nível Superior - Capes, com apoio do Ministério da Educação, criou o Programa Residência Pedagógica (CAPES, 2018) como parte de uma das ações que constituem a Política Nacional de Formação de Professores. O objetivo desse programa é aperfeiçoar o estágio supervisionado curricular obrigatório das licenciaturas, estimulando os graduandos à imersão na escola pública de educação básica nos últimos anos da formação.

Essa imersão abrange regência em sala de aula, intervenção pedagógica e acompanhamento e auxílio ao professor da educação básica, chamado de preceptor no Programa Residência Pedagógica pelo seu papel de supervisor atuante na escola. Todo o processo é orientado por um docente da instituição formadora, denominado orientador, com o intuito de garantir 
habilidades e competências para que seja possível a realização de um ensino de qualidade. Os estudantes de graduação participantes do programa são denominados residentes.

Especificamente no que se refere ao ensino de Ciências para a educação básica, cabe aos residentes dos cursos de licenciatura em Ciências Biológicas atuar de forma a atender os aspectos educativos relacionados ao desenvolvimento de práticas formativas de Biologia, problematização de situações em seu contexto social, produção de novos conhecimentos, ensino por investigação e alfabetização científica, possibilitando, com isso, uma observação crítico-reflexiva mais completa do ambiente escolar e do processo ensino-aprendizagem por parte dos futuros professores.

No campus da Universidade Federal do Espírito Santo situado no município de São Mateus, o programa contemplou, em seu primeiro edital, os cursos de licenciatura em Física, Matemática, Pedagogia e Ciências Biológicas, cabendo a este último atuar no ensino de Ciências para os anos finais do ensino fundamental. De acordo com o Projeto Institucional registrado na Plataforma Freire, da Capes, as ações dos residentes nas escolas campo envolvem: (i) produção de conhecimento e aprendizagem colaborativa; (ii) pesquisa como atitude cotidiana e reflexão como prática formativa; e (iii) práticas investigativas, abordagem CTS e Alfabetização Científica como tendências para o ensino de Ciências e Biologia.

Ainda segundo o Projeto Institucional, a dinâmica de acompanhamento das atividades deve ser guiada, em todas as etapas, pela atenção às demandas escolares, pela prática colaborativa e pela resolução de problemas. Portanto, a partir da identificação das demandas, a expectativa dos participantes do projeto era de alcance da elaboração, execução e avaliação das propostas específicas que visavam tanto à aprendizagem dos estudantes da escola da educação básica quanto à formação dos bolsistas envolvidos.

Nessa perspectiva, o presente trabalho tem por objetivo apresentar algumas propostas educativas realizadas por três graduandas do curso de licenciatura em Ciências Biológicas, autoras do presente artigo, e a sua impressão sobre as atividades desenvolvidas durante a vigência do Programa 
Residência Pedagógica em uma escola municipal de ensino fundamental do município de São Mateus/ES. As impressões das residentes aqui apresentadas foram debatidas com a professora preceptora e o professor orientador, coautores do artigo.

\section{Percurso metodológico}

O subprojeto Biologia/Ufes São Mateus, vinculado ao Projeto Institucional do Programa Residência Pedagógica da Universidade Federal do Espírito Santo, foi desenvolvido entre agosto de 2018 e janeiro de 2020, seguindo o cronograma de etapas sugerido no edital publicado pela Capes (2018). Envolveu ações em três escolas públicas de área urbana localizadas no município de São Mateus, estado do Espírito Santo, sendo uma estadual e duas municipais. As atividades aqui relatadas foram desenvolvidas em uma escola municipal de ensino fundamental, selecionada pela Secretaria Municipal de Educação para ser uma das participantes do programa devido aos seus baixos indicadores educacionais.

Os meses de agosto e setembro foram destinados a realização de reuniões de preparação das três residentes e formação inicial da professora preceptora ${ }^{1}$. Nesta etapa, as reuniões foram realizadas em salas de aula do campus Ufes São Mateus ${ }^{2}$ e envolveram apresentações explicativas sobre o programa, estudos sobre políticas educacionais recentes, incluindo-se a Base Nacional Comum Curricular, e discussões sobre a organização das etapas seguintes.

Nos meses de outubro a dezembro de 2018 ocorreu a etapa de ambientação das residentes, visando uma aproximação com a comunidade escolar, com o cotidiano profissional da professora preceptora e compreensão acerca dos procedimentos administrativos e pedagógicos da escola.

\footnotetext{
1 Apesar de o texto abordar as experiências especificas das autoras deste artigo, ressalta-se que o subprojeto Biologia/Ufes São Mateus do Programa Residência Pedagógica contou com 24 residentes bolsistas, três professores preceptores e um professor orientador. Assim, as reuniões descritas, presididas pelo professor orientador, contaram com a participação de outros residentes e professores preceptores vinculados ao referido subprojeto.

2 Reuniões no campus foram realizadas também durante o ano de 2019, mas de forma esporádica, visando troca de experiências sobre atividades desenvolvidas nas diferentes escolas e eventuais orientações gerais.
} 
Em fevereiro de 2019, com a abertura do ano letivo, foi iniciada a etapa de imersão das residentes, sendo esta a mais prolongada, com atividades que envolveram, inclusive, a regência de classe. Esta etapa foi encerrada em novembro de 2019 , antes das últimas provas do ano letivo.

Os meses finais foram destinados a elaboração de relatórios e trocas de experiências com os demais participantes do Programa Residência Pedagógica desenvolvido pela Universidade Federal do Espírito Santo.

Ao todo, as residentes atuaram junto a professora preceptora durante 18 meses consecutivos, coincidindo com o número de bolsas disponibilizadas pela Capes para cada residente.

As atividades relatadas neste estudo foram realizadas exclusivamente na etapa de imersão e envolveram três graduandas do curso de licenciatura em Ciências Biológicas da Universidade Federal do Espírito Santo, estas, residentes bolsistas, alunos dos $7^{\circ}$ e $8^{\circ}$ anos e a professora preceptora da escola municipal, além do professor orientador do programa.

Por se tratar de um trabalho que buscou a resolução de um problema coletivo, no caso a dificuldade enfrentada pelos estudantes do ensino fundamental em relação a aprendizagem de temas específicos do currículo de Ciências, bem como a formação inicial das residentes e a formação continuada da professora preceptora, sendo um processo participativo e cooperativo, o método de estudo empregado caracteriza-se como pesquisa-ação.

\section{Resultados e discussão}

Os temas do currículo que contaram com intervenções didáticas por parte das residentes foram selecionados, principalmente, a partir do relato da professora preceptora sobre o histórico de dificuldades dos estudantes dos $7^{\circ} \mathrm{e}$ $8^{\circ}$ anos em relação a estes temas. Percebe-se, nesse caso, que os saberes da experiência profissional foram fundamentais para a tomada de decisões sobre que temas do currículo deveriam ser tratados com maior profundidade pelas residentes. Segundo Tardif (2014), saberes provenientes da experiência profissional são aqueles adquiridos na prática do ofício na escola e na sala de aula. Assim, por não vivenciarem por um período mais prolongado o cotidiano 
da escola e, especificamente, das salas de aula, seria difícil para as residentes decidirem sozinhas sobre que elementos do currículo deveriam ser tratados nas intervenções.

Além da experiência da professora preceptora, foram levadas em conta as dificuldades de aprendizagem sobre determinados conteúdos relatadas às residentes pelos próprios alunos.

Assim, percebe-se que para que haja construção do conhecimento é necessário ir além da realização do currículo de maneira verticalizada, em que o professor é considerado detentor do conhecimento e os estudantes apenas apreendem os conteúdos passados pelo professor. É necessário dialogar, compreender o que os estudantes já trazem consigo, instigar a curiosidade e a resolução dos problemas apresentados para que a escola seja, de fato, um local onde haja motivação e o conhecimento seja construído, e não apenas apresentado.

A partir das dificuldades apontadas e da compreensão de que é necessário motivar para que os estudantes desejem participar ativamente do processo de construção do seu conhecimento, foram realizadas as intervenções didáticas relatadas a seguir.

Tema: Citologia

No início do ano letivo de 2019, o primeiro conteúdo abordado foi Citologia. Para uma abordagem didática motivadora, foram usados modelos celulares tridimensionais (célula animal, vegetal, procarionte, organelas celulares, sangue e caliciforme) confeccionados em massa de biscuit (Figura 1) pelo projeto de extensão PROEX/UFES "Formando Pesquisadores: A Biologia Celular na Prática".

A disciplina de citologia é associada à dificuldade de aprendizagem na educação básica, já que trata de estruturas complexas como as organelas celulares (FERNANDES, 1998). Compreender a célula como unidade formadora do corpo de um ser vivo é essencial para aprofundamento no conhecimento biológico. Porém, se faltam recursos tecnológicos, como microscópios, a sua visualização e entendimento se tornam abstratos (PALMERO; MOREIRA, 1999). Então, o uso dos modelos nas aulas pelos 
residentes foi eficaz, visto que os alunos puderam interagir com visão e tato, tendo espaço para perguntar sobre as estruturas e nomenclatura de cada célula.

De acordo com Matos et al. (2009, p. 20),

Modelo didático corresponde a um sistema figurativo que reproduz a realidade de forma esquematizada e concreta, tornando-a mais compreensível ao aluno. Representa uma estrutura que pode ser utilizada como referência, uma imagem que permite materializar a ideia ou o conceito, tornando-os assimiláveis. Os modelos didáticos devem simbolizar um conjunto de fatos, através de uma estrutura explicativa que possa ser confrontada com a realidade.

Figura 1: Modelos tridimensionais em massa de biscuit de células e organelas $(A)$, células do sangue $(B)$ e célula caliciforme $(C)$

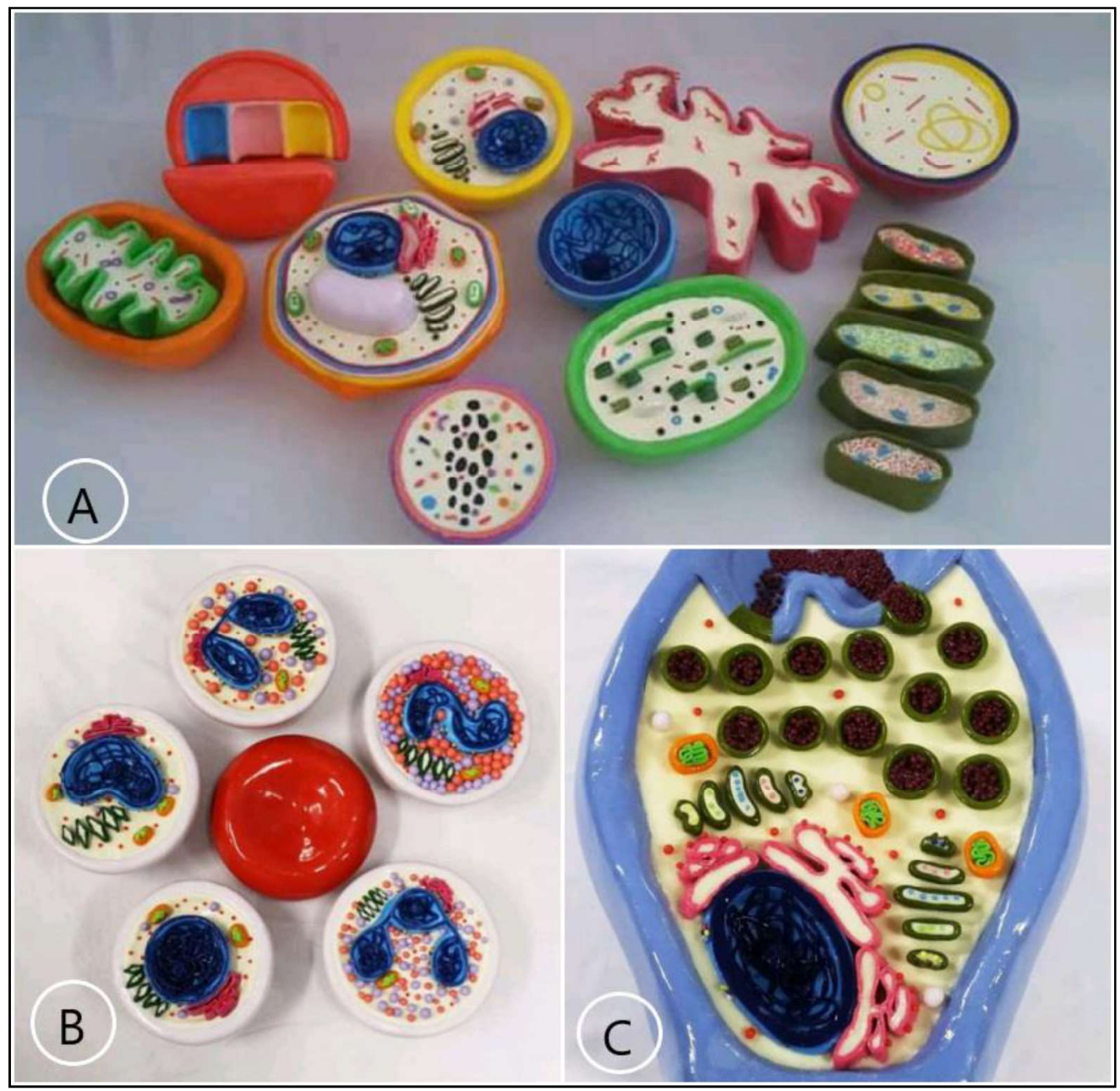

Fonte: Acervo do projeto de extensão "A Biologia Celular na Prática" do CEUNES 
A utilização de modelos tridimensionais auxilia a prática educativa que deve ser sempre estimulada nas escolas, principalmente de ensino fundamental, que é onde o conhecimento científico é visto pela primeira vez. Essa atividade integra aluno e professor e reforça a parceria entre ambos promovendo imaginação, criatividade, estudo em grupo e desenvolvimento social e intelectual (OLIVEIRA et al., 2015).

O conteúdo citologia foi abordado nas turmas de $7^{\circ}$ ano, que é a série em que se aprende sobre a composição dos seres vivos. Nas turmas de $8^{\circ}$ ano foi passado de forma resumida a fim de que retomassem os conhecimentos apreendidos no ano anterior, mas agora de forma prática e visível.

As ações dos residentes juntamente com a professora possibilitaram que os alunos compreendessem que a célula é a unidade básica da vida, sendo composta por estruturas denominadas organelas, cada uma com uma função, e também que os formatos celulares variam conforme o local do corpo.

Os alunos se mostraram atentos a explicação dos modelos, pois foi uma forma lúdica de aprender, indo além das imagens $2 \mathrm{~d}$ dos livros didáticos de ciências, possibilitando questionamentos acerca de estruturas e o manuseio do material didático.

A maior atenção dos alunos no desenvolvido das atividades mostra que as disciplinas precisam ir além da forma teórica, tendo como apoio um conjunto de aulas práticas que aprimorem os saberes. Porém, quando se trata de célula, as escolas não possuem equipamentos e material biológico e, assim, os modelos didáticos cumprem os objetivos e suprem essa lacuna sendo uma alternativa eficaz (MATOS et al., 2009).

Tema: Invertebrados

A dinâmica sobre diferentes grupos de invertebrados envolveu a utilização de modelos tridimensionais fornecidos pelo Núcleo de Bentos Marinho da UFES (Figura 2) e o uso de tecnologias digitais, com imagens chamativas, vídeos explicativos e animações como forma de ilustrar e explicar o que eram esses seres e qual a importância deles no meio ambiente. Para Oliveira (2013), adaptar o contexto das aulas através de slides, vídeos, imagens e animações se torna essencial para um ensino de qualidade. 
Figura 2: Modelos tridimensionais em massa de biscuit de diferentes grupos de invertebrados

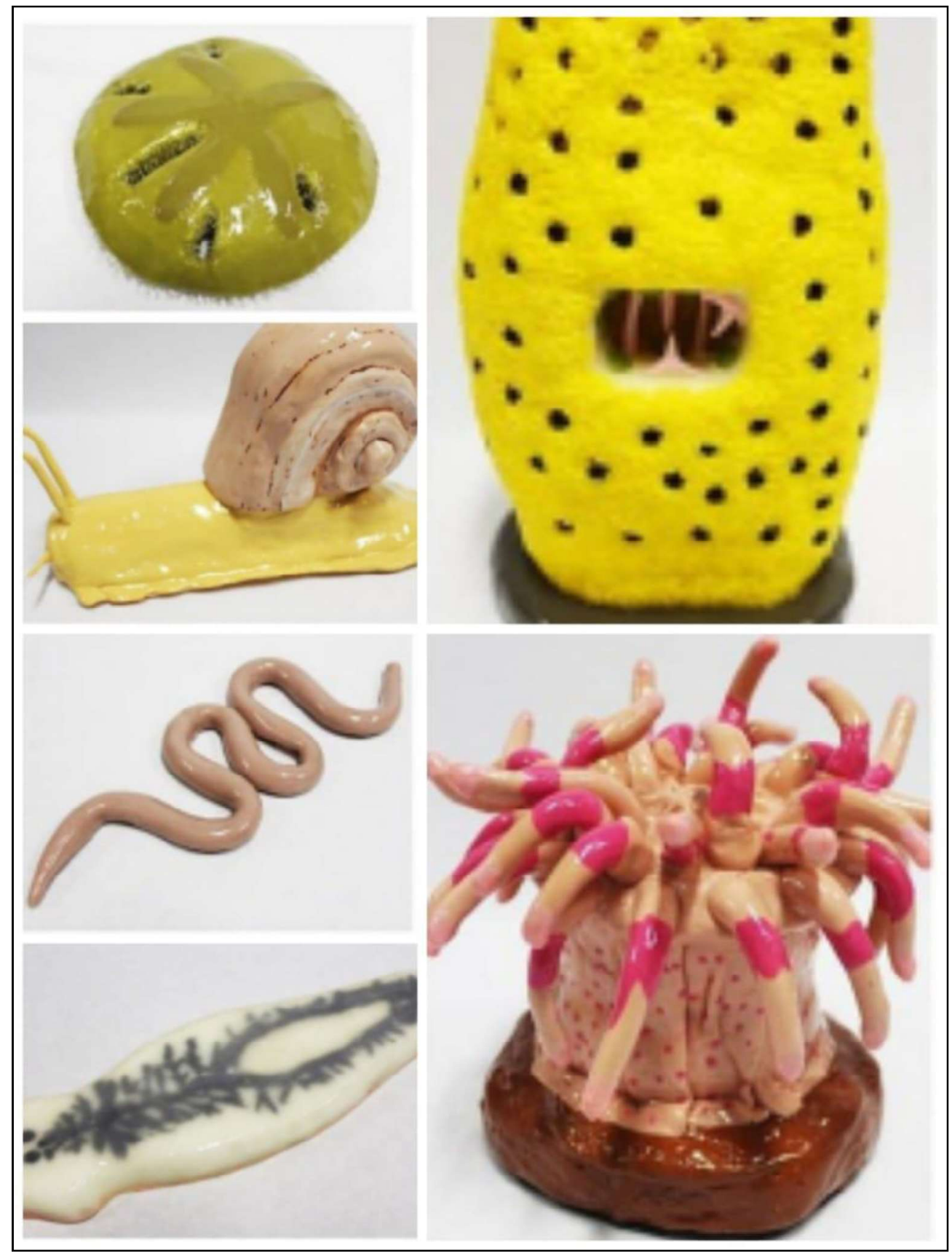

Fonte: Acervo pessoal

A dinâmica inicial para explicação do conteúdo foi realizada em sala de aula e levou em consideração o conhecimento prévio dos alunos e a utilização dos modelos didáticos, o que proporcionou que as aulas corressem de forma participativa. Posteriormente, as aulas ocorreram na sala de informática, tendo como objetivo a revisão e fixação da matéria através de perguntas relacionadas 
ao tema. Desta forma, os alunos puderam expor suas dúvidas e curiosidades, além de identificar características marcantes de cada grupo, espécies representantes dos mesmos e algumas doenças relacionadas.

Ao final das atividades ficou evidenciado que os alunos demonstraram maior interesse em aprender o conteúdo e, a partir da consideração dos conhecimentos prévios dos alunos associada a utilização dos modelos e das aulas expositivas a aprendizagem adquiriu maior significado.

\section{Tema: Sistema Respiratório}

Para ilustrar esse conteúdo os residentes confeccionaram um esquema do sistema respiratório feito em material reciclável, como papelão, jornal, palitos de churrasco, frasco de produto de limpeza e resto de tecido em que a parte do corpo humano foi representada em papelão, sendo o pulmão confeccionado em massa de biscuit (Figura 3). A atividade consistia em os alunos identificarem cada componente do sistema respiratório no esquema e relatar como ocorre o seu funcionamento. Essa atividade teve como propósito auxiliar a fixação do conteúdo com a participação efetiva dos alunos.

O ensino, além de prático, deve ser reflexivo acerca dos materiais usados para a confecção das práticas. A utilização de recursos recicláveis é uma alternativa que vem sendo mais empregada ao longo dos últimos anos, desmistificando-se a ideia de que o descartável é lixo. O conceito de materiais recicláveis vem sendo abrangido para materiais que podem ser reutilizados e assim gerar uma discussão reflexiva acerca da produção e volume de resíduo, interligada a reciclagem e uso desses materiais na educação básica (CORTEZ; ORTIGOZA, 2007).

Figura 3: Modelo do sistema respiratório em materiais recicláveis e massa de biscuit 


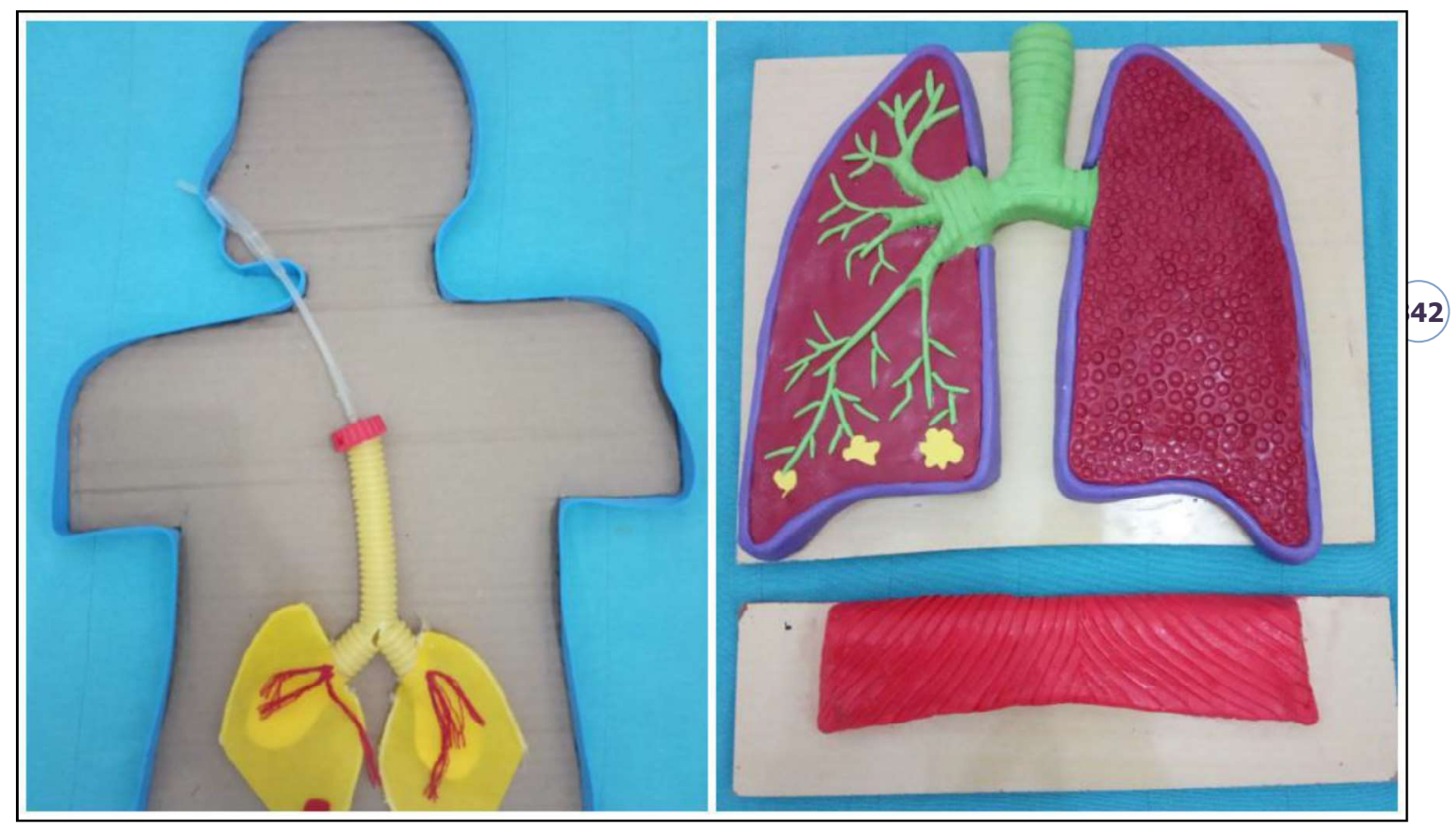

Fonte: Acervo pessoal

Antes de propor a atividade, o conteúdo foi ministrado com auxílio do livro didático, a partir do qual os alunos fizeram resumos e conheceram as estruturas $\mathrm{e}$ as funcionalidades dos órgãos que compunham o sistema respiratório. As dificuldades dos alunos consistiam em entender como o ar externo chega até o pulmão e como as trocas gasosas ocorrem. A partir daí, surgiu a ideia do esquema como alternativa a driblar esse problema enfrentado pelos alunos, visto que a escola não dispõe de material que contribua para fixação e compreensão do conteúdo.

De acordo com Knechtel e Brancalhão (2008, p. 4):

Não há aprendizagem sem atividade intelectual e sem prazer; a motivação através da ludicidade é uma boa estratégia para que a aprendizagem ocorra de forma efetiva. As situações lúdicas mobilizam esquemas mentais além de desenvolver vários aspectos da personalidade como a cognição, afeição, socialização, motivação e criatividade.

Utilizar jogos e esquemas como ferramentas no processo ensinoaprendizagem é fundamental para o desenvolvimento da criatividade $\mathrm{e}$ curiosidade do aluno. A ciência é apresentada muitas vezes pelo uso contínuo do livro didático, o que torna o ensino monótono e cansativo para os educandos que se sentem desestimulados a ter atenção ao que o professor 
está ministrando em sala de aula e, como consequência, não há aprendizado (OLIVEIRA et al., 2015).

O esquema do sistema respiratório é uma alternativa dinâmica que trabalha, na prática, os conceitos vistos na teoria, possibilitando interação entre os alunos, gerando socialização e o sentimento de estar num jogo. A prática possibilitou que os alunos inferissem o interior do corpo humano a partir de um esquema tridimensional manipulável, facilitando o entendimento sobre 0 percurso do ar e por quais estruturas ele passa e como acontecem as trocas gasosas.

\section{Tema: Tecidos Animais}

Este tema foi desenvolvido a partir de dinâmica feita com uma bolinha de papel. A bola percorria as mãos dos alunos, sendo o processo acompanhado por uma música, até que esta fosse pausada. Quem estivesse com a bolinha na mão quando a música parava respondia uma pergunta sobre os tecidos. $A$ atividade ocorreu em sala de aula, onde os alunos foram posicionados em círculo no meio da sala. Os residentes forneceram o aparelho de som utilizado e também modelos didáticos de células musculares (Figura 4) do projeto de extensão "Formando Pesquisadores: A Biologia Celular na Prática", da universidade, para ilustrar o tecido muscular e desenvolveram as questões sobre o tema.

Sobre o recurso aplicado, Hallam (2012) afirma que é necessário diversificar as formas de ensino, sendo a música um recurso que pode ser usado para o processo de aprendizagem nas salas de aula por melhorar a percepção do aluno quanto ao conteúdo. A atividade utilizando música teve como objetivo revisar o conteúdo estudado sobre os tipos de tecidos animais, em que os alunos colocaram em teste a sua aprendizagem em relação às funções e características de cada tecido, de uma forma dinâmica, descontraída e interativa.

Figura 4: Modelos tridimensionais em massa de biscuit de células musculares 


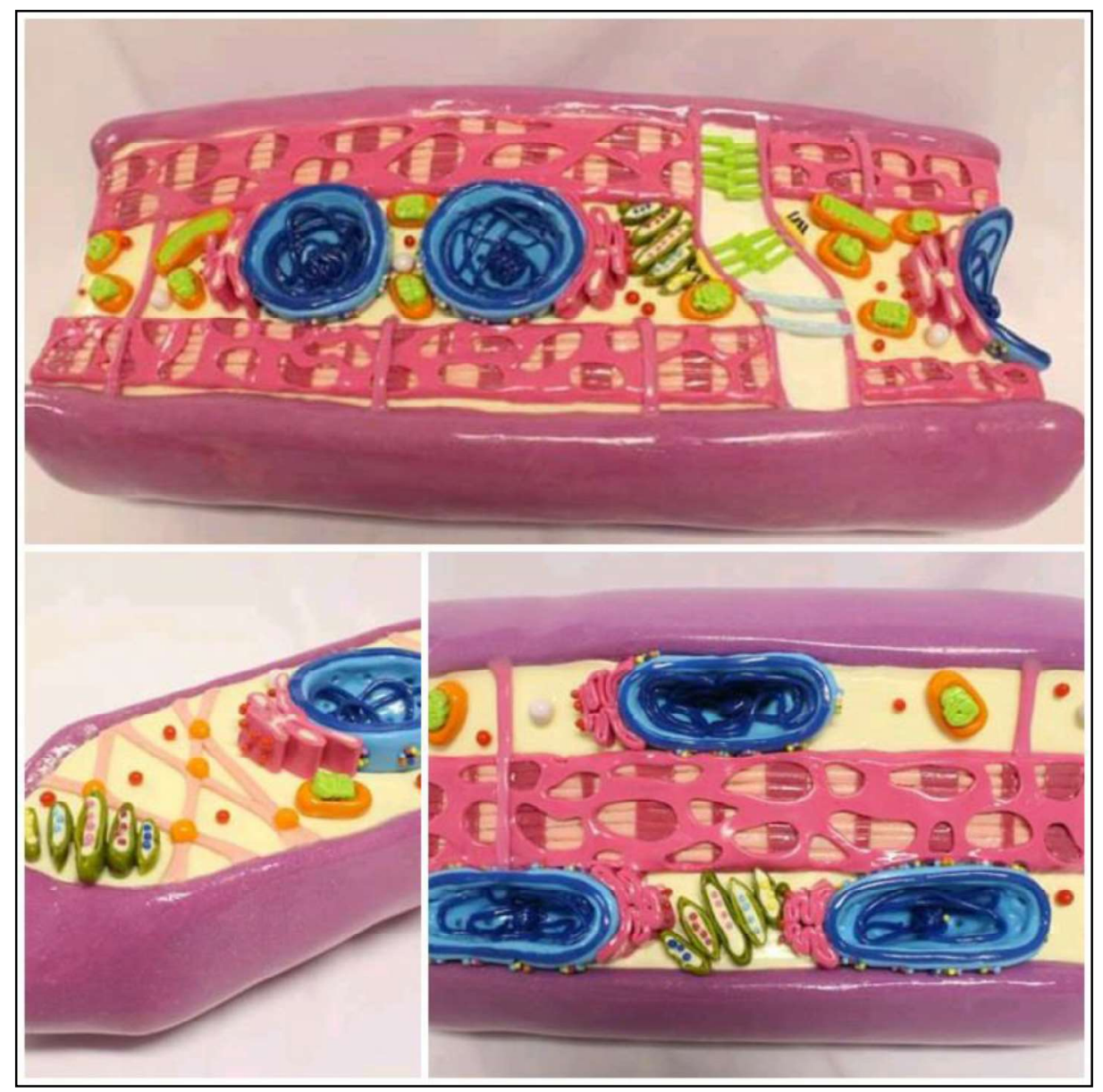

Fonte: Acervo do projeto de extensão "A Biologia Celular na Prática" do CEUNES.

Ao final da atividade os alunos puderam fixar melhor o conteúdo através de aula expositiva. Além disso, a dinâmica promoveu maior interação alunoaluno e professor-aluno. Quando o professor acredita no potencial do seu aluno, ele possibilita a criação de diálogos em que pode surgir uma admiração por parte do aluno e transformar a aprendizagem em processo prazeroso (MALHEIROS, 2020).

Tema: Infecções Sexualmente Transmissíveis (IST)

$\mathrm{Na}$ escola, durante o período de imersão, as residentes tiveram a oportunidade de participar da organização da feira de ciências escolar do ano de 2019. O tema Infecções Sexualmente Transmissíveis foi apresentado em estandes (Figura 5) desenvolvidos pelos alunos dos $8^{\circ}$ e $9^{\circ}$ anos, divididos em grupos de 5 para cada estande, sob orientação das residentes e da preceptora. 
Figura 5: Estandes sobre infecções sexualmente transmissíveis (IST) montados para feira de ciências da escola municipal de ensino fundamental

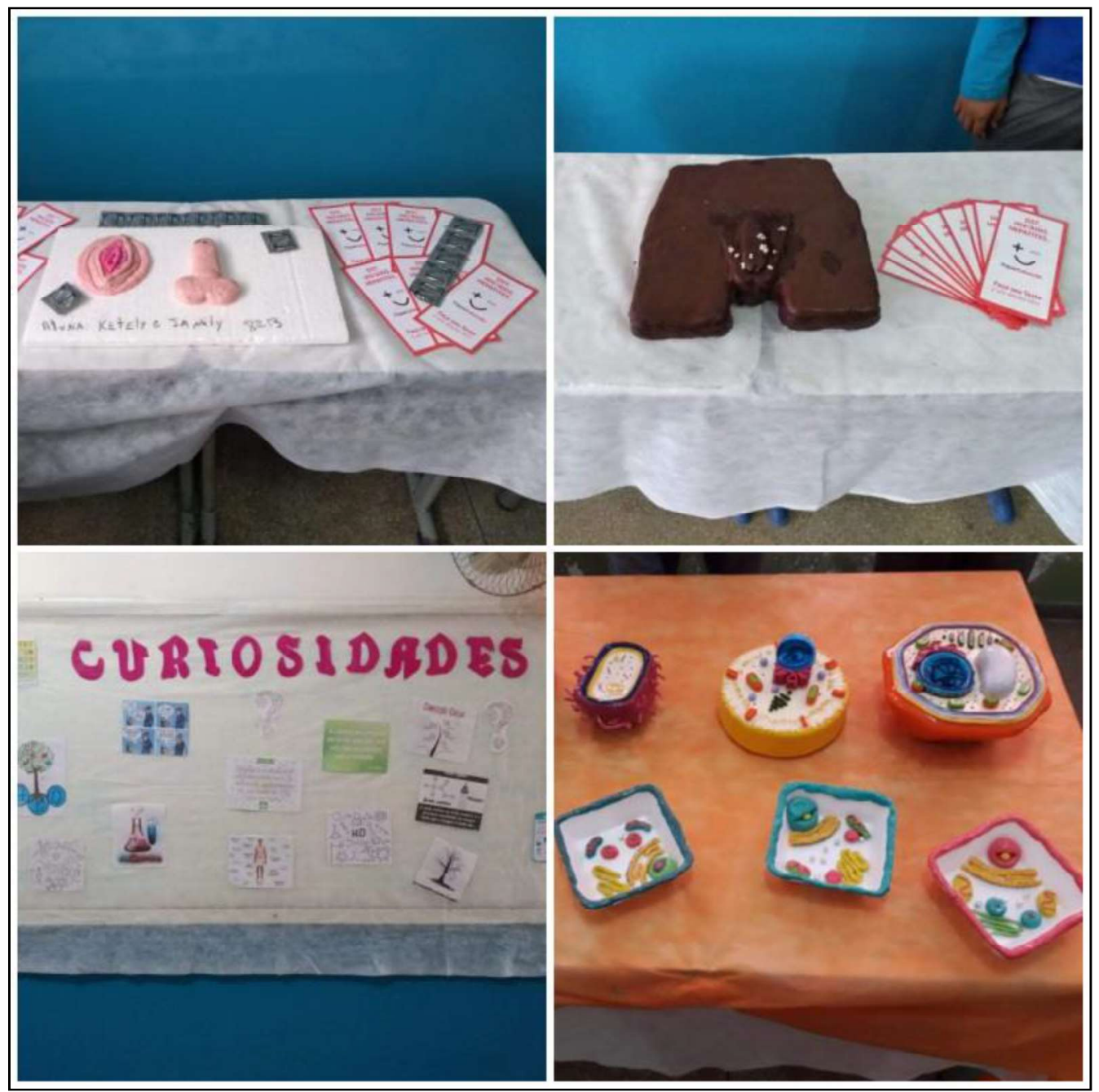

Fonte: Acervo pessoal

Feiras de ciências têm sido cada vez mais comuns em escolas devido a possibilidade de serem desenvolvidas a partir de projetos e do trabalho interdisciplinar. O ensino por projetos implica um olhar diferente do educador em relação ao aluno, acerca do seu próprio trabalho e sobre o rendimento escolar envolvendo fases como planejar, desenvolver e avaliar (BARCELOS, 2001). Já o conhecimento interdisciplinar, segundo Thiesen (2008), é construído a partir de uma visão mais integradora, dialética e totalizadora, rompendo com a visão cartesiana e mecanicista de mundo e de educação.

Além desses aspectos, Freitas (2015) salienta a importância do entretenimento e ludicidade no ensino, e atividades em feiras de ciências 
possibilitam que o trabalho escolar seja desenvolvido de maneira lúdica, tornando-o motivador e despertando maior interesse por parte do aluno em ir à escola e participar das atividades propostas.

Foram usadas 4 salas de aula para que os alunos pudessem montar estandes com o tema IST expondo os materiais feitos por cada grupo. A maioria das carteiras foi retirada a fim de ampliar o espaço para exposição e recepção dos visitantes. Cada grupo abordava o que era a IST apresentada, modo de contágio, como tratar, remédios, como se prevenir e alguns apresentavam uma maquete mostrando a doença ou o vírus. Para a exposição os alunos contaram com apoio de posto de saúde local através da doação de panfletos, banners e contraceptivo não hormonal.

A feira de ciências foi aberta à comunidade local para que as famílias dos alunos pudessem contemplar as atividades por eles desenvolvidas na escola e para que moradores locais pudessem visitar a exposição. Neste dia, todos os professores receberam um cronograma para que conduzissem suas turmas à exposição de forma organizada, otimizando o aproveitamento do que era apresentado pelos alunos expositores.

Neste trabalho todos os alunos puderam aprofundar seus conhecimentos acerca da temática, desenvolvendo saber científico, confrontando-o com o que é abordado no senso comum e desmistificando conceitos errôneos. Além disso, envolveram-se de forma entusiasmada com as atividades por serem participantes ativos da construção do seu próprio conhecimento e pelo potencial lúdico e criativo do processo.

\section{Considerações finais}

A vivência prática proporcionada pelo Programa Residência Pedagógica superou a do estágio supervisionado em função do tempo de dedicação e permanência na escola. Diante disso, foi possível constatar que a formação docente, quando ocorre mais intensamente no local da prática profissional, possibilita que as teorias apresentadas ao longo da graduação sejam mais bem verificadas na prática. Dessa forma, com um olhar crítico-reflexivo, o futuro professor pode testar a viabilidade de seus conhecimentos acadêmicos em 
diferentes circunstâncias de ensino, adquirindo maior segurança para o momento em que efetivamente esteja no exercício da sua profissão.

De fato, o Programa Residência Pedagógica possibilitou que as graduandas residentes colocassem em prática algumas das ferramentas que são estudadas e desenvolvidas na universidade, tanto a partir da teoria quanto da prática laboratorial e extensionista. Na experiência dessas ações, cumpriuse com o objetivo de fortalecer a relação entre instituição de ensino superior e escola da educação básica.

As metodologias didáticas utilizadas e a experiência vivenciada resultaram em efetiva construção do conhecimento, tanto para estudantes do ensino básico quanto para as residentes, além de possibilitarem que a professora preceptora pudesse conhecer novos procedimentos didáticos, aprimorando sua prática profissional.

Para uma educação transformadora é necessário sair da zona de conforto e ir além do método tradicional de ensino, alcançando uma prática pedagógica atraente e envolvente para que a aprendizagem seja significativa e duradora. Ainda que sejam vários os desafios encontrados, a experiência adquirida durante o desenvolvimento do Programa Residência Pedagógica mostra que, para superá-los, é preciso inovar para tornar o processo de ensino mais agradável para estudantes e professores. A profissão docente é muito mais do que apenas transmitir o conteúdo, envolvendo também compreender as limitações, buscar materiais diversos para uso em sala, avaliar de formas variadas e promover a ludicidade, além de formar o aluno considerando os aspectos históricos, sociais, culturais, políticos e econômicos.

Agradecimentos a CAPES pela concessão de bolsas durante o período de atividades, o que permitiu melhores resultados.

\section{Referências}

BARCELOS, N. N. S. A prática e os saberes docentes na voz de professores do Ensino Fundamental na travessia das reformas educacionais. 2001. 143 f. Dissertação (Mestrado em Educação) - Faculdade de Educação, Universidade de São Paulo, São Paulo, 2001. 
CAPES. Edital Capes $n^{\circ}$ 6/2018: Programa de Residência Pedagógica Retificado. Disponível em: https://www.capes.gov.br/images/stories/download/editais/27032018-Edital-6Residencia-Pedagogica-Alteracao-II.pdf.

CORTEZ, A. T. C.; ORTIGOZA, S. A. G. Consumo sustentável: conflitos entre necessidade e desperdício. São Paulo: UNESP, 2007.

DOMINICÉ, P. La formation continue est aussiunrèglement de compte avecsascolarité. Éducation et Recherche, v. 3, n. 86, p. 63-72, 1986.

FERNANDES, H. L. Um Naturalista na Sala de Aula. Ciência \& Ensino, v. 5, p. 3-5, 1998.

FREITAS, J. L. A. Práticas inovadoras de histologia na educação de jovens e adultos. 2015. Dissertação (Mestrado em Ensino na Educação Básica) Universidade Federal do Espírito Santo, 2015. 248 p.

HALLAM, S. Psicologia da música na educação: o poder da música na aprendizagem. Revista de Educação Musical, n. 138, p. 22-39, jan./dez. 2012.

KNECHTEL, C. M.; BRANCALHÃO, R. M. C. Estratégias lúdicas no ensino de Ciências. Paraná, $2008 . \quad$ Disponível em: http://www.diaadiaeducacao.pr.gov.br/portals/pde/arquivos/2354-8.pdf. Acesso em 11/08/2020.

MALHEIROS, T. et al. UMA ABORDAGEM SOBRE A AFETIVIDADE ENTRE PROFESSORE ALUNO NO PROCESSO ENSINO-APRENDIZAGEM. Políticas e práticas em educação, 2020.

MATOS, C.; OLIVEIRA, C. R; SANTOS, M. P.; FERRAZ, C. Utilização de modelos didáticos no ensino de entomologia. Revista de Biologia e Ciências da Terra, v. 9, n. 1, p. 19-23, jan./jun. 2009.

NÓVOA, A. Concepções e práticas de formação contínua de professores. In: NÓVOA, A. (Org.). Formação Contínua de Professores: Realidades e Perspectivas. Aveiro: Universidade de Aveiro, 1991, p. 15-38.

OLIVEIRA, A. M. Uso pedagógico do data show no ensino de Ciências. In: Paraná. Secretaria de Estado da Educação. Superintendência de Educação. Os Desafios da Escola Pública Paranaense na Perspectiva do Professor PDE, 2013. Curitiba: SEED/PR., 2016. V.1. (Cadernos PDE). Disponível em: <http://www.diaadiaeducacao.pr.gov.br/portals/cadernospde/pdebusca/produco es_pde/2013/2013_uem_cien_artigo_adilson_maria_de_oliveira.pdf $>$. Acesso em $11 / 08 / 2020$.

OLIVEIRA, D. B.; PIANCA, B. R.; SANTOS, E. R. MANCINI, K. C. Modelos e atividades dinâmicas como facilitadores para o ensino de biologia. Enciclopédia Biosfera, Goiânia, v.11, n.20, p.514-524, 2015. 
PALMERO, M. L. R.; MOREIRA, M. A. Modelos mentales de la estructura y el funcionamiento de la célula: dos estudios de casos. Investigações em Ensino de Ciências, v. 4, n. 2, p. 121-160, 1999.

PIMENTA, S. G. 1997. Formação de professores - saberes da docência e da identidade do professor. Revista Nuances, v. 3, 1997.

TARDIF, M. Saberes docentes e formação profissional. 17. ed. Petrópolis: Vozes, 2014.

THIESEN, J. S. A interdisciplinaridade como um movimento articulador no processo ensino-aprendizagem. Revista Brasileira de Educação, v. 13, n. 39, p. 545-598, set./dez. 2008.

\section{Sobre os autores}

\section{Brunela Santana}

brunela.sa@hotmail.com

Graduação em Ciências Biológicas Licenciatura pela Universidade Federal do Espírito Santo - UFES - campus São Mateus. Tem experiência na área de biologia celular e histologia com ênfase em educação do nível básico, formação de professores e divulgação científica. Tem experiência na área de Paleontologia e Evolução voltada a modelos didáticos e práticas educativas. Atualmente é monitora no Museu de Ciências da Vida da UFES.

\section{Mayra Gomes Pacheco}

mayrapacheco17@hotmail.com

Graduanda em Ciências Biológicas - Licenciatura pela Universidade Federal do Espírito Santo, campus São Mateus. Participou do projeto de extensão "Formando pesquisadores: A Biologia Celular na Prática", com experiência em produção de materiais didáticos para o ensino de Ciências e Biologia (20172019).

\section{Laís Reges Martins}

lais-reges@outlook.com

Graduanda em Ciências Biológicas - Licenciatura pela Universidade Federal do Espírito Santo, campus São Mateus.

\section{Christiane Vieira de Andrade}

brunela.sa@hotmail.com

Graduação em Ciências Biológicas pelo Centro Universitário Leonardo da Vinci, Brasil (2010). Professora em Designação Temporária da Escola Municipal de Ensino Fundamental Vereador Laurindo Samaritano. 


\section{Gustavo Machado Prado}

gmprado.gmp@gmail.com

Possui graduação em Ciências Biológicas pela Universidade Federal de Viçosa (1997), mestrado (2002) e doutorado (2007) em Ciências Biológicas (Zoologia) pelo Museu Nacional/UFRJ. Atualmente é Professor adjunto no Centro Universitário Norte do Espírito Santo (CEUNES), da Universidade Federal do Espírito Santo, atuando no Programa de Pós-Graduação em Ensino na Educação Básica (Mestrado Acadêmico) e exercendo as funções de Coordenador da Comissão de Estágio Supervisionado das Licenciaturas do CEUNES e membro do Colegiado do curso de Ciências Biológicas (Licenciatura). Desenvolve pesquisa nas áreas de Biodiversidade, Ensino e Currículo. 